\title{
PERFORMANCE, YIELD AND CHARACTERISTICS OF BIOFLOCCULANTS (UPMBF13) PRODUCED BY bacillus subtilis UPMB13 DURING SUBMERGED AND SOLID-STATE FERMENTATION
}

\author{
ZULKEFLEE Z. ${ }^{1,5}$ \\ SHAMSUDDIN Z.H. ${ }^{2}$ \\ ARIS A.Z. ${ }^{3}$ \\ YUSOFF M.K. ${ }^{4}$ \\ KOMILIS D. ${ }^{5, *}$ \\ SÁNCHEZ A. ${ }^{5}$
}

\author{
${ }^{1}$ Department of Environmental Sciences, Faculty of Environmental Studies \\ Universiti Putra Malaysia, 43400, UPM Serdang, Selangor, Malaysia \\ ${ }^{2}$ Department of Land Management, Faculty of Agriculture \\ Universiti Putra Malaysia, 43400, UPM Serdang, Selangor, Malaysia \\ ${ }^{3}$ Environmental Forensics Research Centre, Faculty of Environmental Studies \\ Universiti Putra Malaysia, 43400, UPM Serdang, Selangor, Malaysia \\ ${ }^{4}$ UPM Consultancy and Services Sdn. Bhd., \\ Universiti Putra Malaysia, 43400, UPM Serdang, Selangor, Malaysia \\ ${ }^{5}$ Composting Research Group, Department of Chemical Engineering \\ Escola d'Enginyeria, Universitat Autònoma de Barcelona \\ 08913-Bellaterra (Cerdanyola del Vallès), Barcelona, Spain
}

Received: 26/02/2016

Accepted: $11 / 04 / 2016$

Available online: $24 / 06 / 2016$

*to whom all correspondence should be addressed: e-mail: dkomilis@env.duth.gr

\section{ABSTRACT}

This study compares the distinctive performance, yield and characteristics of bioflocculants (UPMBF13) derived from submerged (SmF) and solid-state fermentation (SSF) of Bacillus subtilis UPMB13. The bioflocculants were subjected to morphological characterization, functional groups determination, molecular weight measurement, protein content quantification and specific compound identification. The SmF and the SSF strategies yielded an average of $2.70 \mathrm{~g} \mathrm{l}^{-1}$ and $1.25 \mathrm{~g} \mathrm{~kg}^{-1}$ of UPMBF13, respectively. The submerged UPMBF13 resulted in a clear suspension with visible flocs formation, while flocs from the SSF treatment were less apparent. Higher total proteinaceous contents of UPMBF13 from the SSF led to the inferiority in flocculating performances. The produced UPMBF13 consisted of hydroxyl, carboxyl, methoxyl and carbonyl functional groups which contributed to their flocculating abilities. The molecular weights of UPMBF13 were around $10-50 \mathrm{kDa}$, characterizing them into low-molecular weight bioflocculants. The submerged UPMBF13 were more fibrous in nature than the SSF, giving the submerged UPMBF13 the upper hand in flocculation. SmF was the best fermentation method yielding high performing bioflocculants at a faster rate by the utilization of non-elaborative techniques. SSF, on the other hand, was proven feasible but further improvements are needed.

Keywords: Bacillus subtilis, Bioflocculants, Solid state fermentation, Submerged fermentation

\section{Introduction}

Bioflocculants are extracellular-polymeric substances with flocculating capabilities, produced naturally by microorganisms during growth (Subramanian et al., 2009). They are recognized as an environmentally friendly alternative in suspended solid treatment applications compared to chemical flocculants that are being scrutinized for their harmful by-products (Muthulakshmi et al., 2013).

Zulkeflee Z., Shamsuddin Z.H., Aris A.Z., Yusoff M.K., Komilis D. and Sánchez A. (2016), Performance, yield and characteristics of bioflocculants (UPMBF13) produced by Bacillus subtilis UPMB13 during submerged and solid-state fermentation, Global NEST Journal, 18(3), 611-620. 
Limitations in commercial application of bioflocculants are mainly due to the implementation costs required in all aspects of their production (Christenson and Sims, 2011). Studies have compared the potentials of submerged (SmF) and solid-state fermentations (SSF) with emphasis on their advantages and disadvantages. Submerged fermentation, due to the minimal hassles required in its handling, monitoring, and overall process and control, is generally preferred (Singhania et al., 2010). However, the SmF process could be more expensive due to the cost of the liquid substrate required. Solid-state fermentation (SSF) is accepted in the production of biopolymers (Thomas et al., 2013) in general, as a substitute to the SmF, but documented evidence on bioflocculant productions specifically through SSF are still lacking. Implementation of SSF aims at curtailing production cost by utilizing readily abundant organic wastes as substrates (Dhillon et al., 2013). Nonetheless, the SSF process could also be a challenge due to the complexity of handling bulk quantities of solid substrates (Abraham et al., 2013). These issues raised uncertainties in controlling and standardizing the fermentation process for regular and continuous bioflocculant production in the long run.

The current study investigated the production of novel bioflocculants named; UPMBF13, by a locally isolated rhizobacterium Bacillus subtilis UPMB13 through both the SmF and SSF processes. To the best of our knowledge, no studies comparing submerged and solid-state fermentation on bioflocculant production have been published. The performance, yield, rate of production and the distinctive characteristics of the bioflocculants produced from both fermentations were compared to understand their flocculating potential and the efficacy of the fermentation strategy. The extraction mechanism for the bioflocculants produced from both the SmF and SSF will be described and their characterizations determined to reflect their flocculating potentials. This information will contribute to the overall understanding of the flocculating abilities of the produced bioflocculants so that to better select the best fermentation strategy to be implemented for continuous production of high quality bioflocculants during suspended solids treatment and commercialization.

\section{Materials and methods}

\subsection{Bacterial strain}

The bioflocculant-producing strain B. subtilis UPMB13 were obtained from the culture collection of the Department of Land Management, Universiti Putra Malaysia (Amir et al., 2003). The rhizobacteria isolated from oil-palm root is an endospore former, Gram positive, motile bacteria with the optimum culture $\mathrm{pH}$ and temperature of 6-7 and $25-40{ }^{\circ} \mathrm{C}$, respectively, when grown in a liquid media of tryptic soy broth (Merck). The strain produces mucoid and ropy colonies on tryptic soy agar (Merck) media but when cultured on nutrient agar (Merck) the colonies formed were devoid of these characteristics. The liquid culture broth bearing the strain is viscous in nature, indicative of the bacterial growth and UPMBF13 production. The validation of the strain using Basic Local Alignment Search Tool (BLAST) program analysis of the nucleotide sequence of the amplified product based on the $16 \mathrm{~S}$ ribosomal ribonucleic acid (rRNA) gene sequencing verified the strain as $B$. subtilis at $99 \%$ similarity. Additional biochemical identification test based on 29 biochemical and enzymatic reaction tests (BBL Crystal Gram-Positive ID System) also proved the strain as $B$. subtilis (99\%).

\subsection{Submerged fermentation}

Batch cultures of the submerged fermentation utilizing $100 \mathrm{ml}$ tryptic soy broth (in triplicates using $250 \mathrm{ml}$ Erlenmeyer flasks) were prepared (Merck, Spain) at 1\% (v/v) inoculation level at the optimal conditions of initial $\mathrm{pH} 7.0$, incubation temperature $25 \pm 2{ }^{\circ} \mathrm{C}$ to $30 \pm 2{ }^{\circ} \mathrm{C}$, and shaking speed of $130 \mathrm{rpm}$ for 24,48 and $72 \mathrm{~h}$. The flocculating capacities of each batch culture were verified through kaolin assays prior to the extraction and purification of UPMBF13 from the cell-free supernatant of the fermentation broth. 


\subsection{Solid-state fermentation}

About $20 \mathrm{~g}$ of substrate in triplicates with $500 \mathrm{ml}$ Erlenmeyer flasks were used for the batch cultures of the solid-state fermentation. The substrate consisted of solely soybean fiber residues (Natursoy, Spain) with the addition of wood chips as the non-nutritive bulking agent at a ratio of 2:1 $(\mathrm{w} / \mathrm{w})$. The optimal fermentation condition was at $5 \%(\mathrm{v} / \mathrm{v})$ inoculation level with an initial $\mathrm{pH}$ of $6.5-7.0$, initial moisture content at $60-65 \%$ and was incubated in a control temperature chamber at $25^{\circ} \mathrm{C} \pm 2{ }^{\circ} \mathrm{C}$ for 24,48 and $72 \mathrm{~h}$ under static mode. Nothing less than $5 \%$ inoculum level was used to decrease the lag phase in UPMB13 growth on the solid substrate, while the level was also ensured not to exceed the optimal initial moisture content level needed for the fermentation. The flocculating capacities of each batch culture were verified through kaolin assays prior to the extraction and purification of the bioflocculants from the filtered substrate suspension. The preparation of the filtered substrate suspension is discussed elsewhere (Zulkeflee and Sánchez, 2014).

\subsection{Extraction and purification}

There is no unified method for bioflocculant extraction (Subramanian et al., 2009). In this study, UPMBF13 produced through the submerged and solid-state fermentations were extracted through ethanol precipitations of the cell-free supernatant and the filtered substrate suspension, respectively at a ratio of 2:1 $(\mathrm{v} / \mathrm{v})$ of the ice cold ethanol $(96 \% \mathrm{v} / \mathrm{v})$ to the bioflocculant source. The mixed solution was left to precipitate overnight at $4{ }^{\circ} \mathrm{C}$ and then collected by centrifugation at $12,000 \times \mathrm{g}$ for $15 \mathrm{~min}$ at $4{ }^{\circ} \mathrm{C}$ before being re-suspended in ultra-pure Milli- $Q$ water. The suspensions were further purified through dialysis against ultra-pure water with a visking tube with a molecular weight cut-off (MWCO) of 12-14 kDa (Kawaguchi and Decho, 2002) at a minimum of three times water change in $24 \mathrm{~h}$ at $4{ }^{\circ} \mathrm{C}$ to separate any impurities. The purified UPMBF13 were then collected through lyophilisation.

\subsection{Flocculation assay}

Flocculating activities of UPMBF13 derived from both fermentation strategies were measured according to the methods explained elsewhere (Zulkeflee and Sánchez, 2014). The flocculating activity was considered both via the clarity of the treated suspension, based on equation (1), and through visual observations of the visible floc formation.

Flocculating activity $(\%)=[(A-B) / A] \times 100$

where: $A$ is the optical density of the blank and $B$ is the optical density of the treated kaolin suspension at $550 \mathrm{~nm}$ using a spectrophotometer. The $\mathrm{pH}$ at the start of the reaction is 5.5, which is the natural $\mathrm{pH}$ of the kaolin suspension without any amendments. Bioflocculants produced by UPMB13 were proven to have a wide $\mathrm{pH}$ tolerance from $\mathrm{pH}$ 4.0-8.0 (Zulkeflee et al., 2012). All measurements were done in triplicates with the mean and standard deviation determined. Significant differences were analyzed through analysis of variance (ANOVA). Differences were considered significant at a $5 \%$ significance level $(p<0.05)$.

\subsection{Total protein content and amino acid derivatives}

The total protein content of the purified UPMBF13 was determined through Bradford assay with bovine serum albumin (BSA) $\left(2 \mathrm{mg} \mathrm{ml}^{-1}\right)$ (Sigma, Spain) as the protein standard. Amino acid derivatizations were determined using Waters Acc-Q Tag method, together with High Performance Liquid Chromatography (HPLC) (Waters, USA). The method utilizes the derivatization reagent named Acc-Q Fluor ${ }^{\text {'m }}$ reagent which consists of 6-aminoquinolyl-N-hydroxysuccinimidyl carbamate (AQC) that derivatizes primary and secondary amines in samples and produces fluorescently labeled amino acid for detection by the HPLC (Samicho et al., 2013). About $0.1 \mathrm{~g}$ UPMBF13 samples were digested with $5.0 \mathrm{ml}$ of $6 \mathrm{~N} \mathrm{HCl}$ for $24 \mathrm{~h}$ at $110^{\circ} \mathrm{C}$. The resulting hydrolysates were added with $4.0 \mathrm{ml}$ of $2.5 \mathrm{mM}$ alpha amino butyric acid (AABA) and $100 \mathrm{ml}$ of de-ionized water and were filtered using Whatman No.1 filter paper and through a syringe filter. A volume of $10 \mu \mathrm{l}$ aliquot from the filtrates was added with $100 \mu \mathrm{AQC}$ reagent and subsequently about $5 \mu \mathrm{l}$ from the mixed solution were injected into the HPLC for each sample. The Waters Acc-Q Tag column 
( $3.9 \mathrm{~mm} \times 150 \mathrm{~mm}$ ) (Waters, USA) was used as the column for the HPLC. The column temperature was set at $36^{\circ} \mathrm{C}$. Acc-Q Tag Eluent A concentrate and $60 \%$ acetonitrile Acc-Q Tag Eluent B were used as the mobile phase at a flow rate of $1 \mathrm{ml} \mathrm{min}{ }^{-1}$. The fluorescence detector excitation wavelength was $250 \mathrm{~nm}$, the emission wavelength was $395 \mathrm{~nm}$, gain and filter set were 1.0 and 1.5 seconds, respectively.

\subsection{Molecular weight determination}

The molecular weights of the extracted UPMBF13 were determined by sodium dodecyl sulfate polyacrylamide gel (SDS-PAGE) electrophoresis (Yong et al., 2011) using a vertical mini gel electrophoresis setup; Bio-Rad Mini-PROTEAN ${ }^{\bullet}$ Tetra cell (Bio-Rad, Spain). The Mini-PROTEAN ${ }^{\bullet}$ TGX $^{\mathrm{T} m}$ precast gel was mounted on the cassette and $1 x$ running buffer was added and allowed to overflow into the mini tank. UPMBF13 samples were diluted at a ratio of 3:1 (v/v) in the sample buffer (Laemmli loading dye) which was priorly added with $\beta$-mercaptoethanol (BME) and then denatured by heating at $95^{\circ} \mathrm{C}$ for $10 \mathrm{~min}$. The denatured samples were then loaded into the respective wells; with the UPMBF13 of the SSF loaded in the second to the fifth well (quadruplicates), followed by the SmF UPMBF13 in the sixth to the ninth well (quadruplicates). The Precision Plus Protein ${ }^{\mathrm{TM}}$ All Blue Standard and Precision Plus Protein ${ }^{\mathrm{Tm}}$ Dual Color Standard (Bio-Rad, Spain) were inserted into the first and the tenth well, respectively, as the molecular weight markers. The electrophoresis was run at $85 \mathrm{~V}$ constant for $1 \mathrm{~h}$ and a half at room temperature. The gel collected was washed with de-ionized water and subsequently fixed with $40 \%$ methanol and $10 \%$ acetic acid mixture for $30 \mathrm{~min}$, followed by $50 \mathrm{ml}$ of Coomassie G-250 staining solution (Bio-Rad, Spain). The gel was left soaked in the staining solution overnight and the visible bands were finally observed when the gel was submerged in de-ionized water.

\subsection{Functional group determination and morphological characterization}

The functional groups of UPMBF13 were determined as pressed potassium bromide, $\mathrm{KBr}$ disks using Fourier Transform Infrared (FT-IR) Bruker Tensor 27 (Bruker Optics, Germany) spectroscopy and the morphological characterization through scanning electron microscope (SEM) EVO-MA10 (Carl Zeiss, Canada). The samples attached onto carbon stubs were gold-coated twice and then examined at an accelerating voltage of $20.0 \mathrm{Kv}$ (Zulkeflee and Sánchez, 2014). Further qualitative determinations of polysaccharide content in UPMBF13 were also determined through the FT-IR analysis.

\section{Results and discussion}

\subsection{UPMBF13 yield, rate of production and flocculating performances}

About $0.90 \mathrm{~g} \mathrm{I}^{-1}$ of purified UPMBF13 can be collected from the liquid broth of the SmF at a minimum 24 $\mathrm{h}$ of incubation and about $1.25 \mathrm{~g} \mathrm{~kg}^{-1}$ from the fermented substrate of the SSF at a minimum of $72 \mathrm{~h}$ of incubation under optimized fermentation conditions. The amount of UPMBF13 recovered in SmF is comparable to the amount of bioflocculant PX collected from Bacillus circulans at $0.78 \mathrm{~g} \mathrm{I}^{-1}$ reported by Li et al., (2009). A notably lower recovery was obtained in SSF when compared to the biopolymer poly- $\gamma$ glutamic acid collected from Bacillus licheniformis, at $9.84 \mathrm{~g} \mathrm{~kg}^{-1}$ (Bajaj et al., 2008).

On a relative basis of the amount of substrate used, the production through SSF yielded approximately $30 \%$ higher UPMBF13 production compared to the SmF. Higher yield obtained in the SSF compared to the $\mathrm{SmF}$ are common in other comparative studies on the SmF and SSF bioproduction of enzymes (Sandhya et al., 2005; Singhania et al., 2010). However, in this study the rate of UPMBF13 production from the SmF was notably faster. This was particularly due to the nature of the liquid substrate which is naturally easier to assimilate for growth, while the solid substrate of the SSF would take a longer period to biodegrade and promote growth and bioflocculant production. It is extrapolated that the $\mathrm{SmF}$ can produce an average of $2.7 \mathrm{~g} \mathrm{l}^{-1}$ of UPMBF13 in $72 \mathrm{~h}$; which is two-fold the value of the UPMBF13 produced by the SSF in the same duration. Therefore, time-wise, it was concluded that UPMBF13 production by $B$. subtilis UPMB13 was more feasible through the SmF strategy. 
Figure 1 depicts the flocculating performances of UPMBF13 of the SmF and the SSF in terms of percentage suspension clarity and flocs formation. The SmF UPMBF13 led to a maximum activity of $95 \%$ with large visible flocs formed while the SSF UPMBF13 had a maximum activity of $71 \%$ with less apparent flocs were observed. The performances comparison was done under optimized flocculation conditions (Zulkeflee et al., 2012).

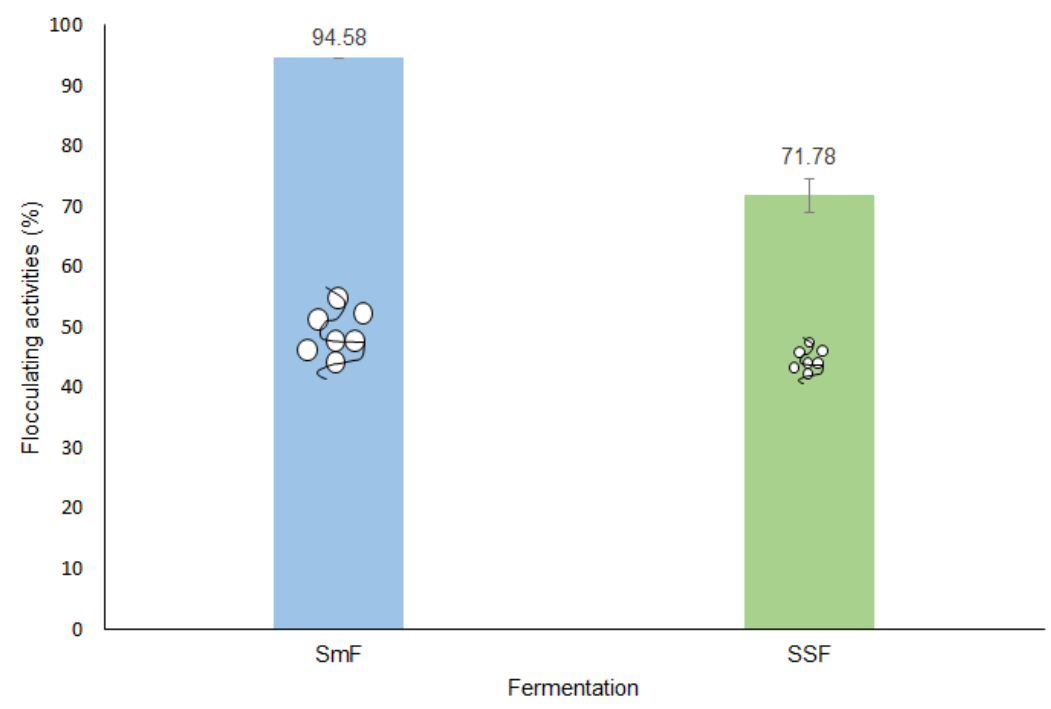

Figure 1. Flocculating activities of UPMBF13 of the SmF and the SSF. The of the flocs formed upon treatment with the bioflocculants.

\subsection{Total proteinaceous content}

About 16 amino acids peaks can be detected through the Waters Acc-Q Tag method, including the internal standard used, AABA, with the exception of cysteine, asparagines and glutamines. Table 1 summarizes the results for free amino acids derivatized from both the SmF and SSF.

UPMBF13 were found to be composed of $6.9 \%(\mathrm{w} / \mathrm{w})$ and $3.6 \%(\mathrm{w} / \mathrm{w})$ protein and of $17.1 \%(\mathrm{w} / \mathrm{w})$ and $46.8 \%(\mathrm{w} / \mathrm{w})$ amino acids from both the SmF and SSF, respectively. Charged anions of weak carboxylic groups are always present on the surfaces of any intra and extracellular proteins (Hess and van der Vegt, 2009). The higher amount of protein and amino acid present would contribute to the additional negative charges in the flocculation system. Therefore, the higher amount of total proteinaceous content (protein and amino acids) of the SSF could contribute to a lower flocculating performance as compared to the UPMBF13 from the SmF due to the overbearing negative charges it possessed. This was proven true in comparing the general performances of UPMBF13 of the SSF that were inferior to that of the SmF (Figure 1).

Glutamic acid was the major fraction of the total amino acid derivatized from UPMBF13 of the SmF at a percentage of $44.7 \%(\mathrm{w} / \mathrm{w})$ followed by lysine at $9.91 \%(\mathrm{w} / \mathrm{w})$. The SSF differed, since the major fraction was found to be lysine, at a percentage of $15.4 \%(\mathrm{w} / \mathrm{w})$ whilst glutamic acid was found second at a $5 \%$ lower quantity. Scrutinizing more, it could be seen that the percentage amount of other free amino acids present in UPMBF13 from SSF were higher compared to the corresponding amounts from the SmF. For example: aspartic acid (7.76\%), glycine (6.17\%), arginine $(4.02 \%)$, threonine $(5.23 \%)$, alanine $(4.44 \%)$, proline $(2.62 \%)$, tyrosine $(2.46 \%)$, valine $(5.16 \%)$, isoleucine $(4.48 \%)$, leucine $(7.31 \%)$, phenylalanine $(5.22 \%)$ and serine $(4.90 \%)$. The high levels of glutamic acid measured in both UPMBF13 sources prove the occurrence of repeated unit of the amino acid forming the poly- $\gamma$-glutamic acid ( $\gamma$-PGA). The $\gamma$-PGA is the only biopolymer produced by $B$. subtilis strains that has been reported to have flocculating capabilities (Bhunia et al., 2012). Therefore, the bioflocculants from B. subtilis UPMB13 was confirmed to be consisted of $\mathrm{Y}$-PGA as one of the important flocculating fractions. 
Table 1. Free amino acid composition of $0.1 \mathrm{~g}$ UPMBF13 of the SmF and SSF

\begin{tabular}{ccc}
\hline Amino Acid & SmF amount (ng) & SSF amount (ng) \\
\hline Glutamic acid & 7.67 & 5.65 \\
\hline Lysine & 1.70 & 8.42 \\
\hline Aspartic acid & 0.91 & 4.25 \\
\hline Serine & 0.83 & 2.68 \\
\hline Threonine & 0.82 & 2.86 \\
\hline Glycine & 0.81 & 3.37 \\
\hline Leucine & 0.70 & 4.00 \\
\hline Valine & 0.64 & 2.82 \\
\hline Alanine & 0.58 & 2.43 \\
\hline Arginine & 0.55 & 2.20 \\
\hline Phenylalanine & 0.49 & 2.86 \\
\hline Isoleucine & 0.47 & 2.45 \\
\hline Proline & 0.35 & 1.43 \\
\hline Tyrosine & 0.33 & 1.34 \\
\hline Methionine & 0.27 & - \\
\hline Histidine & 0.16 & - \\
\hline
\end{tabular}

\subsection{Molecular weight}

Molecular weight is one of the most important determinants of flocculating activity of a polymeric flocculant (Ji et al., 2010). The visualizations of the molecular bands showed that the molecular weight of UPMBF13 of the SmF was between 10-50 kDa while for the SSF the molecular weight was around 10-37 $\mathrm{kDa}$ (Figure 2); characterizing the SmF UPMBF13 as a higher molecular weight bioflocculant than the SSF. The difference in colour intensities of the bands from the SSF samples could be due to interference from the buffer used or even from the dye when it comes in contact with the proteins of the sample. This is because proteins interact differently with protein stains even at identical protein loads (http://www.biorad.com/en-sg/applications-technologies/sds-page-analysis). However, this is not observed for the SmF samples. Samples giving lower intensity bands than the other might be due to the protein forming soluble aggregates. Moreover, different staining intensities could also be due to different cell densities of the samples (Greer et al., 2010).

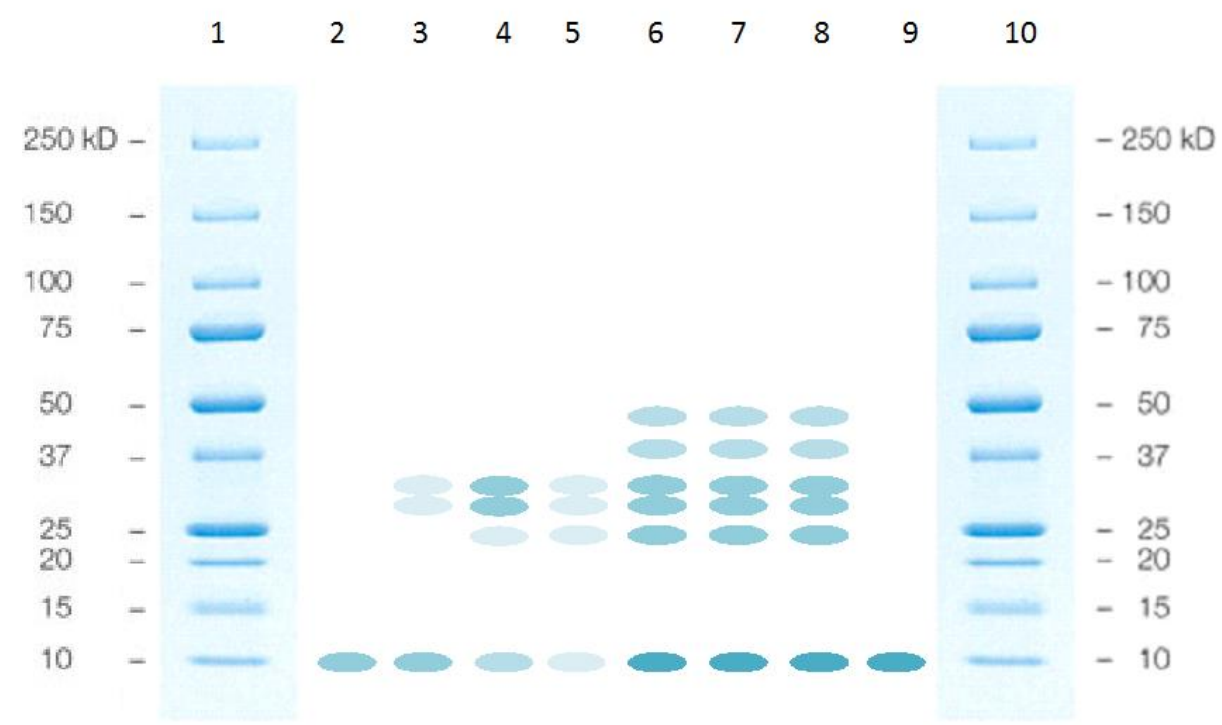

Figure 2. Molecular weight of UPMBF13 of the SSF (well number 2 to 5 ) and the SmF (well number 6 to 9) left overnight in de-ionized water, re-drawn from the stained gel obtained from the electrophoresis 
The increase in polymer molecular weight would lead to a higher molecular polymeric adsorption capacity (O'Shea et al., 2010), hence better flocculating performances. Therefore, the relatively higher molecular weight of the SmF UPMBF13 would lead to a better flocculating performance as compared to the SSF. Nevertheless, UPMBF13 from both sources are still considered to be low-molecular weight bioflocculants with high flocculating capacities in comparison to other reported low-molecular weight bioflocculants produced by Agrobacterium sp. M-503 at $8.1 \times 10^{4}$ Da. (Li et al., 2010).

\subsection{Functional groups and polysaccharide presence}

Overall interpretations of the infrared spectra are in accordance with the approach by Coates (Coates, 2000). Referring to Figure 3(a) of the infrared spectrum of UPMBF13 from the SmF, the broad absorption peak at $3255 \mathrm{~cm}^{-1}$ exhibits the characteristic of O-H band of the hydroxyl functional group (Ntsaluba et al., 2013). The weak peak at $2923 \mathrm{~cm}^{-1}$ indicates the presence of aliphatic $\mathrm{C}-\mathrm{H}$ stretching from methylene group, while the peaks at $1574 \mathrm{~cm}^{-1}$ and $1447 \mathrm{~cm}^{-1}$ showed the stretching band of the carboxyl group (COO-) originated from phenols or tertiary alcohols (Ntsaluba et al., 2013). The $1316 \mathrm{~cm}^{-1}$ and $1262 \mathrm{~cm}^{-1}$ peaks imply the occurrence of $\mathrm{C}-\mathrm{O}$ bond of the carboxyl group and $\mathrm{P}=\mathrm{O}$ bend of the phosphoramide group, respectively.
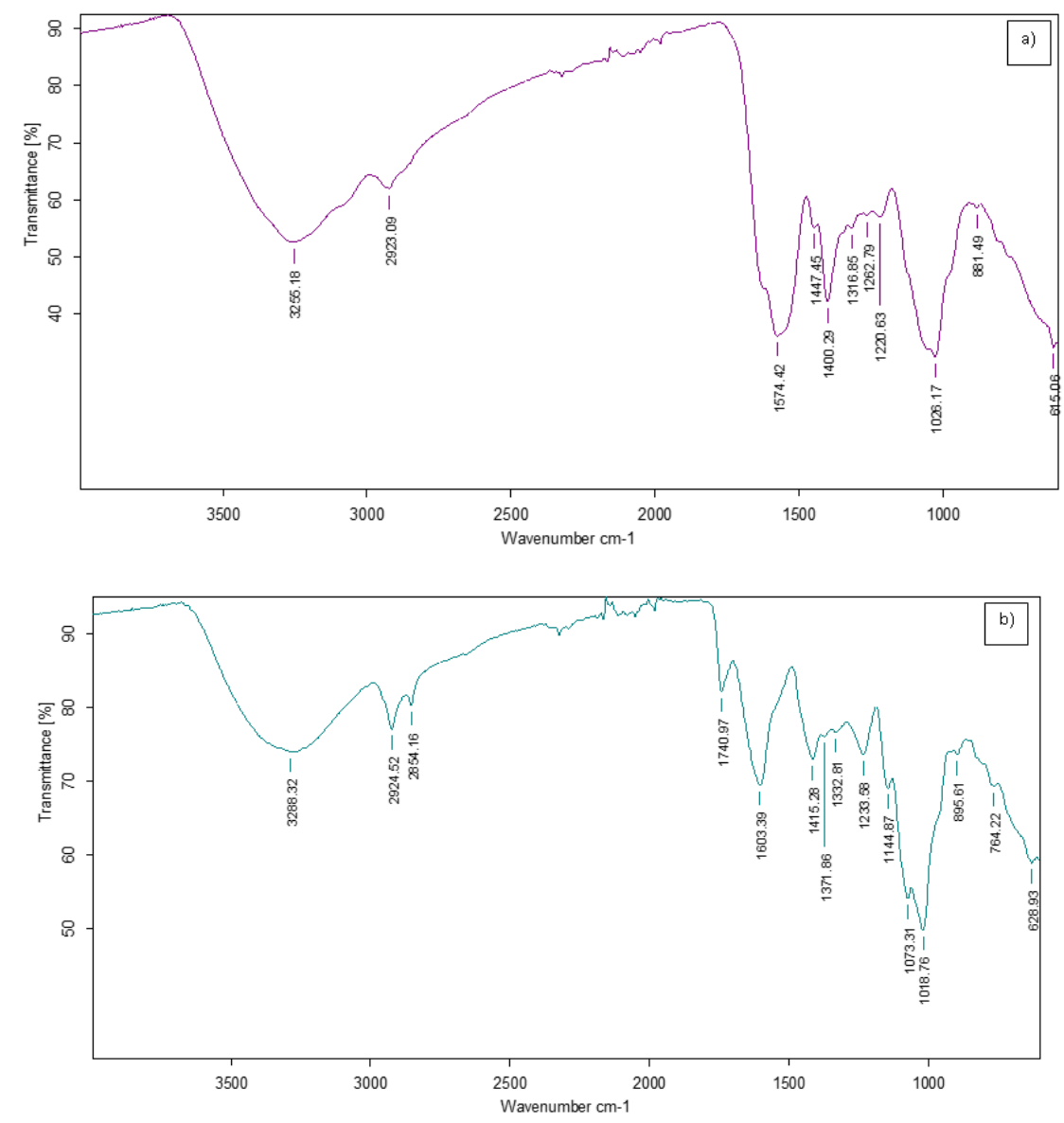

Figure 3. Infrared spectra of UPMBF13 derived from (a) SmF and (b) SSF

The infrared spectrum of UPMBF13 from the SSF in Figure $3(\mathrm{~b})$ showed the wide stretching at $3288 \mathrm{~cm}^{-1}$ and the sharp spike at $2924 \mathrm{~cm}^{-1}$ are characteristics of hydroxyl and methylene functional groups, respectively. The small peak at $2854 \mathrm{~cm}^{-1}$ shows the presence of methyl ether group (Coates, 2000). A modest spike at $1740 \mathrm{~cm}^{-1}$ indicates the presence of the carbonyl functional group (C=O) (Li et al., 2009). The $1603 \mathrm{~cm}^{-1}$ and $1415 \mathrm{~cm}^{-1}$ stretch are naturally carboxyl in nature. Sulfur-oxy compounds presence could be detected by the weak bend at $1371 \mathrm{~cm}^{-1}$ and $1332 \mathrm{~cm}^{-1}$ in the form of dialkyl sulfones or organic sulfates (Coates, 2000). The $1233 \mathrm{~cm}^{-1}$ peak shows the occurrence of carboxyl group. Sharp spikes at 
$1073 \mathrm{~cm}^{-1}$ and $1018 \mathrm{~cm}^{-1}$ together with a smaller spike at $1144 \mathrm{~cm}^{-1}$ signify the presence of methoxyl groups (Aljuboori et al., 2013). The occurrence of intense peaks in the area of $1200 \mathrm{~cm}^{-1}$ to $800 \mathrm{~cm}^{-1}$, the fingerprint region of sugars ( $\mathrm{Wu}$ and $\mathrm{Ye}, 2007$ ), portrayed in both spectra suggest the presence of polysaccharide in UPMBF13, concluding the missing flocculating fraction apart from the $\gamma$-PGA.

In general, the infrared spectra from both sources show the presence of hydroxyl, carboxyl, methoxyl, and carbonyl groups, which are the key functional groups in flocculation processes (Wu and Ye, 2007). These groups provide charged binding sites suitable for aggregation and flocs formation of the suspended colloidal particles by the added bioflocculant (Ntsaluba et al., 2013).

\subsection{Morphological characteristics}

The microscopic images of the surface morphological characteristics of UPMBF13 obtained through the SmF and SSF are depicted in Figure 4(a) and Figure 4(b), respectively.

The images from both sources appeared identical with some distinct features which could be seen captured at different angles. Generally, UPMBF13 are naturally fibrous in nature with thin and broad crust-like flake structures observed through higher magnification. The fibrous nature of UPMBF13 is more apparent for the SmF compared to the SSF. It can also be noticed that smooth globular or cylindrical structures are present together and are interlinked between the crust-like formations at some angles. These notably are the attributes of $\mathrm{Y}$-PGA (Yang et al., 2011).
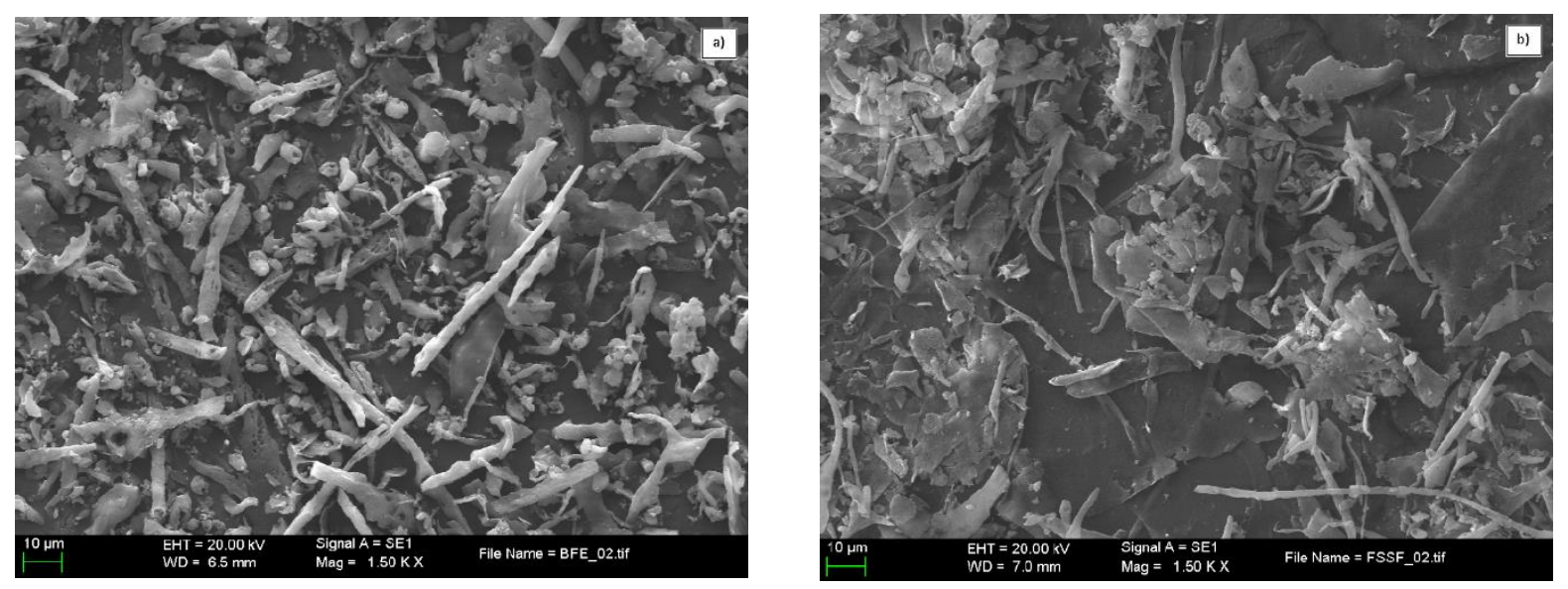

Figure 4. Microscopic images of UPMBF13 of (a) SmF: and (b) SSF

\section{Conclusions}

The SmF and SSF strategies yielded an average of $2.70 \mathrm{~g} \mathrm{I}^{-1}$ and $1.25 \mathrm{~g} \mathrm{~kg}^{-1}$ of UPMBF13, respectively after $72 \mathrm{~h}$ fermentations. The compositional fraction of UPMBF13 includes protein at $6.9 \%(\mathrm{w} / \mathrm{w})$ and $3.6 \%$ $(\mathrm{w} / \mathrm{w})$ and amino acids at $17.1 \%(\mathrm{w} / \mathrm{w})$ and $46.8 \%(\mathrm{w} / \mathrm{w})$ from both the SmF and SSF, respectively. The flocculating fractions of the bioflocculants are concluded to be polysaccharides and $\gamma$-PGA. The average molecular weights of the bioflocculants from both sources ranged between $10 \times 10^{3} \mathrm{Da}$ to $50 \times 10^{3} \mathrm{Da}$, thus characterizing them to be high-performing low-molecular weight bioflocculants. Furthermore, the bioflocculants were justified to possess all four key functional groups in a good flocculation system, namely the hydroxyl, carboxyl, methoxyl and carbonyl groups. The bioflocculants were observed to be fibrous with broad and thin crust-like structure, which provide the bridging mechanism in bioflocculation. In general, the attributes of the SmF bioflocculants were superior to the SSF ones. Thus, the SmF is the best fermentation strategy to be implemented for continuous production of high performing bioflocculants in the long run. Further cost related studies could be done to improve the SmF strategy through non-elaborative techniques and through utilization of cheaper substrates to ensure cost- 
effectiveness of its implementation. Furthermore, more studies are needed for the SSF strategy to improve the performances of the bioflocculant produced.

\section{Acknowledgements}

This work was supported by the Ministry of Higher Education, Malaysia under the Fundamental Research Grant Scheme [02/04/10/832FR], the Spanish Ministerio de Economía y Competitividad [Project CTM2015-69513-R] and the European Commission under the Erasmus Mundus Action 2 Plan (MAHEVA Project) scholarship program. Dimitrios Komilis thanks Techniospring for the financial support.

\section{References}

Abraham J., Gea T. and Sanchez A. (2013), Potential of the solid-state fermentation of soy fibre residues by native microbial populations for bench-scale alkaline protease production, Biochemical Engineering Journal, 74, 15-19.

Aljuboori A.H.R., Idris A., Abdullah N. and Mohamad R. (2013), Production and characterization of a bioflocculant produced by Aspergillus flavus, Bioresource Technology, 127, 489-493.

Amir H.G., Shamsuddin Z.H., Halimi M.S., Ramlan M.F. and Marziah M. (2003), N2 fixation, nutrient accumulation and plant growth promotion by rhizobacteria in association with oil palm seedlings, Pakistan Journal of Biological Science, 6, 1269-1272.

Bajaj I., Lele S. and Singhal R. (2008), Enhanced production of poly ( $\gamma$-glutamic acid) from Bacillus licheniformis NCIM 2324 in solid state fermentation, Journal of Industrial Microbiology and Biotechnology, 35, 1581-1586.

Bhunia B., Mukhopadhy D., Goswami S., Mandal T. and Dey A. (2012), Improved production, characterization and flocculation properties of poly $(\gamma)$-glutamic acid produced from Bacillus subtilis, Journal of Biochemical Technology, 3, 389-394.

Christenson L. and Sims R. (2011), Production and harvesting of microalgae for wastewater treatment, biofuels, and bioproducts, Biotechnology Advances, 29, 686-702.

Coates J. (2000), Interpretation of infrared spectra, a practical approach, In: Encyclopedia of Analytical Chemistry, Meyers R.A. (Ed.), John Wiley and Sons Ltd, UK.

Dhillon G.S., Kaur S. and Brar S.K. (2013), Perspective of apple processing wastes as low-cost substrates for bioproduction of high value products: a review, Renewable and Sustainable Energy Reviews, 27, 789-805.

Greer S., Honeywell R., Geletu M., Arulanandam R. and Raptis L. (2010), Housekeeping genes; expression levels may change with density of cultured cells, Journal of Immunological Methods, 355, 76-79.

Hess B. and van der Vegt N.F.A. (2009), Cation specific binding with protein surface charges, Proceedings of the National Academy of Sciences, 106, 13296-13300.

Ji B., Zhang X.Y., Li Z., Xie H.Q., Xiao X.M. and Fan G.J. (2010), Flocculation properties of a bioflocculant produced by Bacillus licheniformis, Water Science and Technology, 62, 1907-1913.

Kawaguchi T. and Decho A.W. (2002), Isolation and biochemical characterization of extracellular polymeric secretions (EPS) from modern soft marine stromatolites (Bahamas) and its inhibitory effect on $\mathrm{CaCO}_{3}$ precipitation, Preparative Biochemistry and Biotechnology, 32, 51 - 63.

Li Q., Liu H., Qi Q., Wang F. and Zhang Y., (2010), Isolation and characterization of temperature and alkaline stable bioflocculant from Agrobacterium sp. M-503, New Biotechnology, 27, 789-794.

Li Z., Chen R.W., Lei H.Y., Shan Z., Bai T., Yu Q. and Li H.L. (2009), Characterization and flocculating properties of a novel bioflocculant produced by Bacillus circulans, World Journal of Microbiology and Biotechnology, 25, 745-752.

Muthulakshmi L., Nellaiah H. and Busi S. (2013), Production and characterization of a novel bioflocculant from Klebsiella sp., Current Biotechnology, 2, 53-58.

Ntsaluba L., Nwodo U.U., Mabinya L. and Okoh A. (2013), Studies on bioflocculant production by a mixed culture of Methylobacterium sp. Obi and Actinobacterium sp. Mayor, BMC Biotechnology, 13, 1-7. 
O'Shea J.P., Qiao G.G. and Franks G.V. (2010) Solid-liquid separations with a temperature-responsive polymeric flocculant: effect of temperature and molecular weight on polymer adsorption and deposition, Journal of Colloid and Interface Science, 348, 9-23.

Samicho Z., Mutalib S.R.A. and Abdullah N. (2013), Amino acid composition of droughtmaster beef at various beef cuts, Agricultural Sciences, 4, 61-64.

Sandhya C., Sumantha A., Szakacs G. and Pandey A. (2005), Comparative evaluation of neutral protease production by Aspergillus oryzae in submerged and solid-state fermentation, Process Biochemistry, 40, 2689-2694.

Singhania R.R., Sukumaran R.K., Patel A.K., Larroche C. and Pandey A. (2010), Advancement and comparative profiles in the production technologies using solid-state and submerged fermentation for microbial cellulases, Enzyme and Microbial Technology, 46, 541-549.

Subramanian S.B., Yan S., Tyagi R.D. and Surampalli R.Y. (2009), Bioflocculants, In: Sustainable Sludge Management, Tyagi R.D., Surampalli R.Y., Yan S., Zhang T.C., Kao C. M. and Lohani B.N. (Eds.), American Society of Civil Engineers. USA.

Thomas L., Larroche C. and Pandey A. (2013), Current developments in solid-state fermentation, Biochemical Engineering Journal, 81, 146-161.

Wu J.Y. and Ye H.F. (2007), Characterization and flocculating properties of an extracellular biopolymer produced from a Bacillus subtilis DYU1 isolate, Process Biochemistry, 42, 1114-1123.

www.bio-rad.com/en-sg/applications-technologies/sds-page-analysis (Last access: 30/03/2016)

Yang X. and Wang H. (2011), Preparation and characterization of $\gamma$-poly(glutamic acid) copolymer with glycol diglycidyl ether, In: Proceedings of the $12^{\text {th }}$ International Conference on Environmental Science and Technology, IACSIT Press, SG.

Yong X., Raza W., Yu G., Ran W., Shen Q. and Yang X. (2011), Optimization of the production of poly-Y-glutamic acid by Bacillus amyloliquefaciens $\mathrm{C} 1$ in solid-state fermentation using dairy manure compost and monosodium glutamate production residues as basic substrates, Bioresource Technology, 102, 7548-7554.

Zulkeflee Z., Aris A.Z., Shamsuddin Z.H. and Yusoff M.K. (2012), Cation dependence, pH tolerance, and dosage requirement of a bioflocculant produced by Bacillus spp. UPMB13: flocculation performance optimization through kaolin assays. The Scientific World Journal, 2012, 1-7. doi 10.1100/2012/495659.

Zulkeflee Z. and Sánchez A. (2014), Solid-state fermentation of soybean residues for bioflocculant production in a pilot-scale bioreactor system, Water Science and Technology, 70, 1032-1039. 